\title{
Controversies in Off-pump Coronary Artery Surgery
}

\author{
John Pepper, M.Chir, FRCS
}

\begin{abstract}
Motivated by a desire to reduce the morbidity of a well-established and effective procedure for coronary artery disease, up to $25 \%$ of coronary artery bypass operations are being performed without the use of a heart-lung pump. Concerns remain about the quality of the coronary anastomoses and the completeness of revascularization. Randomized trials have not revealed the significant reduction in morbidity or mortality that the early enthusiasts had hoped for. Yet a number of non-randomized studies have shown clinical benefit from the avoidance of an extracorporeal circulation, but these have been criticized for potential bias in patient selection and management. A majority of surgeons have not yet adopted this technique and are waiting for the accumulation of more evidence.
\end{abstract}

Keywords: Coronary artery bypass; Coronary disease/surgery; Postoperative complications; Vascular patency; Risk factors; Morbidity; Mortality

$\mathrm{C}$ oronary artery bypass surgery remains an established form of treatment for coronary artery disease. The majority of coronary surgical procedures are performed for multiple vessel disease. In the United Kingdom, 96\% of all coronary bypass surgery involved two or more grafts during the period from 2001 to 2003. ${ }^{1}$ Results following multiple vessel coronary surgery are excellent with 2-year re-intervention rates of only $6 \%$ and a cumulative risk of death and myocardial infarction of $12 \%$ over 2 years post-surgery. ${ }^{2}$

Although the mortality rate of coronary artery surgery is low, at approximately $2 \%,{ }^{1}$ it is age related and rises to over $6 \%$ in those over 75 years of age. This benefit is offset by a complication rate of $20 \%$ to $30 \%$. In addition, there is a 2 to 3 month period of recovery from the fatigue that usually follows any major operation. The recent observation of neurocognitive impairment in up to $42 \%$ of patients 5 years after surgery has aroused additional concern. 3,4 The functional significance of the neurocognitive findings and the relative contribution of aging, atherosclerotic disease, and surgical procedures to the measured impairment remain unknown.

Reprint Requests: John Pepper, M.Chir, Department of Surgery, Royal Brompton Hospital, 2004 Sydney Street, London SW3 6NP, United Kingdom Telephone: 44-20-735I-8530, Fax: 44-20-735I-8530

Email: J.Pepper@rbh.nthames.nhs.uk
Patients and their physicians desire a low morbidity procedure, preferably without general anesthesia and in an outpatient setting. These factors together with the avoidance of the adverse consequences of cardiopulmonary bypass have been the driving force behind the development of percutaneous coronary intervention (PCI). Recurrent angina and the need for subsequent re-intervention are more frequent after PCI than after conventional coronary artery bypass surgery, a performance gap that is likely to be narrowed by the emergence of drug-eluting stents.

PCI has had a dramatic effect on coronary artery bypass surgery, arresting the dramatic growth of surgery in the 1980 s and shifting the attention of surgeons to patients with more advanced coronary disease and extensive coexisting conditions. This has motivated surgeons to refine coronary revascularization techniques in order to maximize clinical effectiveness, limit costs, and reduce invasiveness.

In contrast to the small incision approaches, off-pump coronary artery bypass surgery through a median sternotomy has gained clinical acceptance and in many centers constitutes $20 \%$ to $30 \%$ of the total volume of coronary surgery. Creation of the distal anastomoses is facilitated by the use of stabilizers that reduce the motion of the heart in an

Received: October II, 2004

Revised: December 14, 2004

Accepted: December 28, 2004 
area of approximately $2 \mathrm{~cm}^{2}$. The argument in favor of this approach is to avoid the historical, well-documented adverse effects of cardiopulmonary bypass on end-organ function: coagulation, renal impairment, lung injury and, most important in the ageing population, avoidance of stroke, delirium, and more subtle neurocognitive changes. The counter-argument is that potential suboptimal exposure and hemodynamic instability during off-pump procedures could produce inferior shortand long-term outcomes.

\section{Clinical Outcome}

The distinction between on-pump and off-pump coronary artery surgery is over-simplistic since both methods encompass a range of techniques. On-pump coronary surgery may be performed on the beating heart without the need for a cross-clamp and at various temperatures. Even when an aortic cross-clamp is employed, myocardial protection can be achieved by a wide variety of cardioplegic techniques or by non-cardioplegic methods. The use of composite arterial grafting can minimize aortic manipulation in on-pump surgery and eliminate it completely in the off-pump situation. Calafiore et al. ${ }^{5}$ have shown that avoidance of aortic manipulation is at least as important as the avoidance of cardiopulmonary bypass in reducing the risk of brain injury.

Early randomized studies performed on low-risk patients have shown a shorter length of stay, a reduced use of transfusion products, a reduced incidence of coagulopathy, and a lower frequency of atrial fibrillation in patients who undergo off-pump coronary artery surgery. ${ }^{6-8}$ Although the use of blood products was reduced in the off-pump group $(3 \%$ versus $13 \%)$ and the release of creatine kinase-MB (CK-MB) isoenzyme was $41 \%$ less in the off-pump group, there were no differences in the perioperative complication rates. There was no difference in outcome in the first 1 to 3 years after surgery between off-pump and standard groups. 6,7 A meta-analysis of 6 studies including 558 patients randomized to "on-pump" and 532 to "off-pump" found no significant difference in the combined end-point of death, stroke, or myocardial infarction. ${ }^{9}$ However, there is some evidence that off-pump surgery increases the risk of recurrent angina and the need for re-intervention, suggesting poor graft quality or incomplete revascularization. ${ }^{10,11}$ In patients with three-vessel disease, the completeness of revascularization is a significant determinant of the relief of symptoms over a 5 -year period. ${ }^{12}$

Mack et al. ${ }^{13}$ conducted a retrospective review of a 5-year experience with 12,540 patients who underwent isolated coronary bypass grafting; $15 \%$ of these patients $(n=1,915)$ underwent off-pump surgery. A gradual increase in the percentage of coronary operations performed off-pump was observed from $1.2 \%$ in 1995 to $34.1 \%$ in 2000 . Individual surgeon adoption rates increased from $1 \%$ to $96 \%$ by the end of the study period and the mortality rate in off-pump surgery decreased to $3.2 \%$ compared with an overall observed mortality rate of $4.0 \%$ in the 5 years before the start of their off-pump experience. There was a significant difference in observed mortality between the off-pump and on-pump groups $(1.9 \%$ versus $3.5 \%, P<0.001)$, despite a higher mean predicted risk among the patients in the off-pump group (3.13\% versus $2.8 \%, P<0.004)$. Furthermore, there was less morbidity in the off-pump group as evidenced by a reduced need for blood products $(28.5 \%$ versus $54.7 \%$, $P=0.0001)$, prolonged ventilation $(5.83 \%$ versus $10.93 \%$, $P=0.001$ ), and a shorter hospital stay (6 days versus 7 days, $P=0.001$ ). One of the questions this study was designed to answer was whether off-pump surgery can be safely incorporated into a surgical practice and be performed by most surgeons. In the Dallas practice studied, 13 there were 22 surgeons of whom 6 were enthusiastic early and persistent adopters of the off-pump approach and who carried out $73 \%$ of all off-pump procedures. Eight of the 22 surgeons did fewer than 10 off-pump operations per year. In the 5-year period before the introduction of off-pump procedures, the composite mortality rate of coronary artery surgery for the 3 surgeons with the lowest off-pump adoption rate was $38 \%$ greater than the composite mortality rate of the 3 surgeons with the highest rate of off-pump surgery adoption $(4.0 \%$ versus $2.9 \%, P<0.001)$. As Bonchek points out in his accompanying editorial, ${ }^{14}$ off-pump surgery was being performed predominantly by the most accomplished surgeons. Although off-pump surgery can be safely incorporated into a large practice, it seems unlikely that it will be used on a regular basis by most surgeons. The use of off-pump coronary artery bypass surgery is not widespread and is estimated by the Northern New England Cardiovascular Disease Study Group to be only $8.8 \% .{ }^{15}$

In smaller surgical units, unless there is a core of enthusiasm, it seems unlikely that many surgeons will adopt the technique. The exponential rise in the use of PCI with drug-eluting stents gives rise to a situation in which there is a dearth of low-risk patients requiring double or single bypass grafts and who might be considered for off-pump surgery early in a surgeon's experience. An alternative approach is to adopt the technique wholesale after a period of intense training or "re-engineering" as pursued by Sergeant and colleagues. 16

Mack and colleagues ${ }^{17}$ recently reported a large retrospective study encompassing four centers over a 3-year period. The study examined 17,401 isolated coronary artery bypass procedures, of which 7,283 (41.9\%) were off-pump and 10,118 (58.1\%) were on-pump. Patients were selected for an off-pump procedure on one or more of the following factors: female gender (55\% versus $44 \%$ ), pre-existing renal failure ( $57 \%$ versus $43 \%)$, and repeat procedure $(52 \%$ versus $47 \%)$. The operative mortality rate was $1.9 \%$ for off-pump and $3.5 \%$ for on-pump $(P<0.001)$. To counter the criticism of case selection, 11,548 patients were matched by propensity scoring which produced operative mortality figures of $2.8 \%$ off-pump versus $3.7 \%$ on-pump $(P<0.001)$. 
Table 1. Graft patency after off-pump coronary surgery.

\begin{tabular}{|c|c|c|c|c|c|}
\hline Author & $\mathbf{N}$ & $\%$ Cohort & Patency on-pump (\%) & Patency off-pump (\%) & $\begin{array}{c}\text { Absolute difference } \\
\qquad(95 \% \mathrm{Cl})\end{array}$ \\
\hline Nathoe 26 & 281 & 25 & 93 & 91 & $2.0(6.5-10.4)$ \\
\hline Khan23 & 103 & 80 & 98 & 88 & $10(3.8-16.2)$ \\
\hline Puskas 24 & 185 & 81 & 95.8 & 93 & $2.2(6.1-1.7)$ \\
\hline
\end{tabular}

The use of an on-pump technique was predictive for mortality in repeat procedures, females, and patients over 75 years of age. These authors also found that the use of an off-pump technique was associated with a significantly reduced morbidity. Specifically, there were significant reductions in: the use of blood transfusion ( $32.6 \%$ versus $40.6 \%, P<0.001$ ), the incidence of stroke $(1.45 \%$ versus $2.1 \%, P<0.002)$, and the incidence of postoperative renal failure $(2.6 \%$ versus $5.2 \%, P<0.001)$. There were reductions in pulmonary complications ( $4.1 \%$ versus $9.5 \%, P<0.001$ ), the incidence of postoperative atrial fibrillation $(21.1 \%$ versus $24.99 \%$, $P<0.001)$, and gastrointestinal complications $(3.6 \%$ versus $4.8 \%, P<0.02)$.

The midterm results of a retrospective analysis of off-pump versus on-pump coronary artery surgery were recently published by Sabik et al. ${ }^{18}$ The analysis compared 481 patients who underwent off-pump coronary artery surgery with 3,231 who received their grafts on-pump. Propensity matching was used to match 406 patients from each group. Follow-up was $95 \%$ complete. Four-year survival was $87.5 \%$ after off-pump and $91.2 \%$ after on-pump coronary artery bypass grafting $(P=0.2)$. Likewise, there was no significant difference between the groups in freedom from myocardial infarction (92.6\% off-pump versus $95.7 \%$ on-pump), freedom from PCI (94.3\% off-pump versus $95.5 \%$ on-pump, $P=0.9)$, or freedom from surgical re-intervention $(98.1 \%$ off-pump versus $99.0 \%$ on-pump, $P=0.4$ ). Thus the mid-term outcomes were equivalent, but, interestingly, fewer bypass grafts in the off-pump patients did not decrease survival or increase the incidence of ischemic events.

A recent meta-analysis conducted by van der Heijden et al. ${ }^{19}$ examined 18 randomized trials involving 1,584 patients. Favorable results were found for off-pump coronary artery bypass surgery with the combined endpoint of mortality, stroke, and myocardial infarction, although none of the risk reductions reached statistical significance. As the risk of mortality in both off-pump and on-pump coronary surgery is around $1 \%$, it is unlikely that a significant difference in mortality will be found in patients who are generally low risk. To find a mortality difference of $0.1 \%$, very large trials of $>400,000$ patients will be required. Such trials are an enormous and expensive undertaking and, therefore, unlikely to happen.
Completeness of Revascularization and Graft Patency In observational studies published before 2000, the number of grafts performed off-pump tended to be less than that on-pump..$^{20,21}$ In the recent era this situation has changed. Completeness of revascularization has been reported in only four randomized trials. Czerny et al. ${ }^{22}$ reported significantly reduced completeness of revascularization for off-pump versus on-pump, whereas Khan et al., ${ }^{23}$ Puskas et al., ${ }^{24}$ and van Dijk et al. ${ }^{25}$ reported no difference. The use of an index of completeness (number of grafts performed/number of grafts planned) is a more precise measure and was similar in the two groups. ${ }^{23,24}$

In a study of 281 low-risk patients randomly assigned to either off-pump or on-pump surgery, Nathoe et al. ${ }^{26}$ reported that off-pump and on-pump coronary bypass surgery were equivalent with respect to perioperative and 1-year survival and freedom from stroke, myocardial infarction, and coronary re-intervention. Postoperative angiography was carried out in $64 \%$ of the patients one year after operation. The overall patency rates (Fitzgibbon grade A or B) were $93 \%$ in the on-pump group and $91 \%$ in the off-pump group (table 1). Khan and colleagues ${ }^{23}$ showed a significant reduction in graft patency $(98 \%$ versus $88 \%)$ in an off-pump study group. In this randomized trial involving 103 patients, $80 \%$ received follow-up angiography 3 months after surgery. The majority of the reduced patency occurred in the radial grafts. These results may reflect the experience of a learning curve, as the surgeons had a 2-year experience preceding the trial during which $13 \%$ of their coronary operations had been performed off-pump. Half-dose heparinization at $150 \mathrm{mg} / \mathrm{kg}$ was used in this study rather than the full-dose typical of the on-pump technique, and may have played a role in the lower patency rates in the off-pump group.

Puskas ${ }^{24}$ reported a single surgeon series of 200 patients in which $81 \%$ of 1 -year survivors ( $78 \%$ of the enrolled patients) underwent coronary angiography 1 -year postoperatively. The overall patency rate was $95.8 \%$ on-pump and 93.6\% off-pump, an insignificant difference (table 1). Patency between groups was similar at 1-year among all arterial conduits, all vein grafts, and among grafts to all regions of the heart. This is clearly an excellent series, but as a single surgeon experience it may not be generalizable to all surgical practices. 
Procoagulant activity may be increased after off-pump surgery. 27,28 This may explain the few isolated reports of reduced vein graft patency after off-pump operations. ${ }^{29,30}$ Current practice in experienced centers is to use full-dose heparinization $(300 \mathrm{mg} / \mathrm{kg})$ supplemented throughout the procedure and to use aspirin during and after the operation. Because of the hypercoagulable state after off-pump surgery, it may be wise to use postoperative clopidogrel for the first 3 months. ${ }^{31}$

\section{Risk of Cerebral Injury}

Patients of advanced age and those with other risk factors for neurological complications are being referred for coronary artery surgery in increasing numbers. The challenge persists to get these patients safely through their operation without cerebral injury. At the outset, it was hoped that avoiding cardiopulmonary bypass would markedly reduce the stroke incidence, but evidence to support this hope has been slow to emerge. Early studies failed to show a benefit for off-pump surgery, probably because the numbers of patients enrolled were too small. ${ }^{32}$ Other studies have shown a stroke benefit, particularly in patients with known cerebrovascular disease. $21,33,34$

Three randomized trials have not firmly established a significant difference in neurological outcomes between off-pump and on-pump coronary artery surgery. $6,35,36$ These patients were not stratified according to high-risk aortic disease, so the relative value of off-pump surgery in such patients is not known. But in patients with significant ascending aortic atheromatous disease, it would seem wise to consider an "off-pump" and "no-touch aortic" technique.

Sergeant and colleagues ${ }^{16}$ analyzed a consecutive series of 3,333 patients undergoing coronary artery surgery $(1,593$ on-pump and 1,740 off-pump). They found a trend towards a $60 \%$ reduction of stroke, which after risk adjustment, fell below the level of significance for the total population, but the benefit persisted for patients with severe stenosis of the internal carotid artery. In a meta-analysis of 9 observational studies, ${ }^{37}$ off-pump coronary surgery was associated with a significantly lower incidence of stroke in patients over 70 years of age as compared to the on-pump technique $(1 \%$ versus $3 \%)$, with an odds ratio of $0.38 \%(95 \% \mathrm{CI}=0.22$ to 0.65$)$. The incidence of atrial fibrillation was examined in another meta-analysis of eight non-randomized studies, which included 3,017 patients (764 off-pump and 2,253 on-pump). ${ }^{38}$ The incidence of postoperative atrial fibrillation was significantly less in the off-pump compared to on-pump (odds ratio $0.70 ; 95 \% \mathrm{CI}=0.56-0.89$ ) in an elderly population over 70 years of age. If this finding can be confirmed by a large-scale randomized trial, it would have major implications for the operative strategy in coronary surgery of the elderly.

Why should atrial fibrillation be more frequent in on-pump versus off-pump patients? There are several potential mechanisms. Ischemia with off-pump is regional, whereas with on-pump it is usually global, which may have a detrimental effect on the atrial myocardium resulting in the generation of arrhythmias. Left ventricular segmental wall motion and blood supply to the sub-endocardium and interventricular septum have been found to be better in patients undergoing on-pump compared to off-pump surgery. ${ }^{39}$ This may be important in patients with impaired left ventricular function as atrial dilatation may occur increasing the risk of atrial fibrillation. During off-pump surgery there is less manipulation of the right atrium, as there is no need to insert a cannula. Finally the inflammatory response, which can occur with cardiopulmonary bypass, may result in lung injury and renal injury. The resulting disturbance in acid-base balance and electrolytes may produce atrial irritability leading to atrial fibrillation.

A more common form of cerebral injury is cognitive dysfunction, which affects $40 \%$ to $60 \%$ of cardiopulmonary bypass patients, but resolves in an overwhelming majority by the third postoperative month. ${ }^{40}$ Although it has no obvious immediate impact on clinical outcome, it does correlate with late impairment in quality of life. ${ }^{5} \mathrm{~A}$ third form of cerebral injury is delirium or encephalopathy, which is often thought to be self-limiting. Taggart ${ }^{40}$ points out that this is unjustified complacency as revealed by three recent prospective studies $^{3,41,42}$ (table 2). A recent prospective study of delirium in a group of 16,000 cardiac surgical patients over a 5-year period has been reported by Bucerius et al. ${ }^{43}$ The overall incidence of delirium was $8 \%$ and the study confirmed the adverse consequences that follow: ventilator dependency, sternal instability, and prolonged hospital stay. The frequency of delirium varied with the type of cardiac surgery performed: $8 \%$ among 8,917 patients undergoing conventional on-pump coronary artery surgery; $11 \%$ among 5,424 patients undergoing any type of open heart surgery, including valve replacement; and $2 \%$ among 1,847 patients undergoing off-pump coronary surgery. The authors conclude that the off-pump approach should be considered as one of the strategies for minimizing cerebral injury in coronary artery surgery. The only flaw in their argument is that most of the postoperative risk factors for delirium were significantly lower in the off-pump group. Nevertheless, this study is suggestive that an off-pump strategy, especially in the elderly, is an important method for reducing the risk of cerebral injury.

\section{Quality of Life and Socio-Economic Factors}

Three randomized studies failed to demonstrate significant differences in measures of quality of life after 1 to 4 years of follow-up from off- or on-pump coronary artery surgery. $8,25,44$ Nathoe and colleagues 26 examined symptoms and quality of life at 1-year postoperatively that were equivalent in the on-pump and off-pump groups. They also documented a significant $14 \%$ cost savings with off-pump as compared with on-pump surgery, representing an important cost benefit. 
Table 2. Mortality and morbidity resulting from stroke or delirium.

\begin{tabular}{|c|c|c|c|c|c|}
\hline Author & $\mathbf{N}$ & Operation & Cerebral Injury & Incidence \% & Mortality \% \\
\hline \multirow[t]{3}{*}{ Roach $^{41}$} & 2108 & CABG & None & 94 & 2 \\
\hline & & & Stroke & 3.1 & 21 \\
\hline & & & Delirium & 3.0 & 10 \\
\hline \multirow[t]{3}{*}{ McKhann 42} & 2711 & CABG & None & 91 & 1.4 \\
\hline & & & Stroke & 2.7 & 22 \\
\hline & & & Delirium & 6.9 & 7.5 \\
\hline \multirow[t]{3}{*}{ Wolman 3} & 273 & Open heart $\pm \mathrm{CABG}$ & None & 84 & 7.4 \\
\hline & & & Stroke & 8.4 & 30.4 \\
\hline & & & Delirium & 7.3 & 5.0 \\
\hline
\end{tabular}

CABG, coronary artery bypass graft.

Of four non-randomized trials reporting quality of life, 2 showed no difference ${ }^{44,45}$ and 1 showed significant improvement in quality of life ${ }^{46}$ with off-pump compared to on-pump surgery. One recent randomized trial ${ }^{25}$ reported no significant difference in quality of life 4 to 6 weeks after off-pump versus on-pump. Ascione and colleagues 47 found no significant difference between patients randomized to on-pump or off-pump coronary surgery at 2 to 4 years postoperatively. Questionnaires were sent to 379 survivors who had participated in two randomized trials; response rate was $86.5 \%$. Among those who responded, there was a tendency for questionnaire scores of coronary revascularization outcome (core total, physical and psychosocial functioning, and satisfaction with treatment) to deteriorate with time after the operation $(P<0.05)$.

An analysis of two randomized controlled trials showed a significant cost reduction for off-pump surgery. ${ }^{7}$ But, due to systematic differences between different health care systems and hospitals, costs are highly variable. It is likely that optimal reduction in resource utilization for off-pump surgery will require significant reorganization of each hospital's cardiac surgery service and clinical pathway in order to take advantage of reduced morbidity after off-pump coronary surgery.

\section{Off-Pump Surgery in High-Risk Patients}

There are no reports of selected high-risk patients, but evidence from the American College of Cardiology (ACC)/American Heart Association (AHA) 2004 Guideline Update for Coronary Artery Bypass Graft Surgery 48 for mixed risk (high and low) surgical patients shows level A evidence (data derived from multiple randomized clinical trials or meta-analyses) of similar risk of mortality and level B evidence (data derived from a single randomized trial or non-randomized studies) of reduced risk of mortality at 30 days post-surgery for off-pump surgery. At 1 to 3 years of follow-up, mortality is similar between groups (evidence levels A and B). In high-risk coronary patients, the left ventricle is often dilated. The retraction of large beating hearts, necessary for the off-pump technique, is often poorly tolerated and may require inotropic drugs. An alternative approach is to do these procedures on-pump but without a period of global ischemia or cardioplegia. By decompressing the heart with some form of left ventricular vent and using the stabilization devices, excellent exposure is obtained and both mitral regurgitation and subendocardial ischemia are minimized.

\section{Conclusion}

The intense interest in the modern development of beating heart surgery for coronary artery disease has been fueled by the expectation that morbidity compared to cardiopulmonary bypass would be dramatically lower. That this has not been apparent from several randomized trials has surprised many, but may reflect all the small, subtle improvements in anesthetic and surgical techniques and equipment (e.g., design of pumps, oxygenators, and cannulae) that have taken place over the last 10 years. In high-risk groups, particularly those with renal impairment, off-pump surgery makes the need for postoperative renal support less likely. In groups over 70 years of age, there is a reduction in the incidence of cerebral injury when an off-pump technique is employed.

It is also apparent that off-pump surgery is an exacting technique that takes time to perfect, but can produce a graft quality equivalent to that obtained on-pump. The only real contraindication to off-pump surgery is poor target vessels with a likelihood to require endarterectomy, but in experienced hands even this is a relative contraindication.

The future of off-pump surgery will probably be a slow increase from the present figure of one-third to possibly two-thirds of coronary surgical candidates in the next 10 years. Off-pump coronary surgery is as safe as on-pump surgery, and in experienced hands offers less early complications, particularly in those patients with significant comorbidity. 


\section{References}

1. Keogh B, Kinsman R. Fifth national adult cardiac surgical database report 2003: improving outcomes for patients. Oxfordshire UK: Dendrite Clinical Systems; 2004.

2. SoS Investigators. Coronary artery bypass surgery versus percutaneous coronary intervention with stent implantation in patients with multivessel coronary artery disease (the Stent or Surgery trial): a randomised controlled trial. Lancet 2002;360:965-970.

3. Wolman RL, Nussmeier NA, Aggarwal A, Kanchuger MS, Roach GW, Newman MF, Mangano CM, Marschall KE, Ley C, Boisvert DM, Ozanne GM, Herskowitz A, Graham SH, Mangano DT. Cerebral injury after cardiac surgery: identification of a group at extraordinary risk. Multicenter Study of Perioperative Ischemia Research Group (McSPI) and the Ischemia Research Education Foundation (IREF) Investigators. Stroke 1999;30:514-522.

4. Newman MF, Grocott HP, Mathew JP, White WD, Landolfo K, Reves JG, Laskowitz DT, Mark DB, Blumenthal JA; Neurologic Outcome Research Group and the Cardiothoracic Anesthesia Research Endeavors (CARE) Investigators of the Duke Heart Center. Report of the substudy assessing the impact of neurocognitive function on quality of life 5 years after cardiac surgery. Stroke 2001;32:2874-2881.

5. Calafiore AM, Di Mauro M, Teodori G, Di Giammarco G, Cirmeni S, Contini M, Iaco AL, Pano M. Impact of aortic manipulation on incidence of cerebrovascular accidents after surgical myocardial revascularization. Ann Thorac Surg 2002; 73:1387-1393.

6. van Dijk D, Nierich AP, Jansen EW, Nathoe HM, Suyker WJ, Diephuis JC, van Boven WJ, Borst C, Buskens E, Grobbee DE, Robles De Medina EO, de Jaegere PP; Octopus Study Group. Early outcome after off-pump versus on-pump coronary bypass surgery: results from a randomized study. Circulation 2001;104:1761-1766.

7. Angelini GD, Taylor FC, Reeves BC, Ascione R. Early and midterm outcome after off-pump and on-pump surgery in Beating Heart Against Cardioplegic Arrest Studies (BHACAS 1 and 2): a pooled analysis of two randomised controlled trials. Lancet 2002;359:1194-1199.

8. Puskas JD, Williams WH, Duke PG, Staples JR, Glas KE, Marshall JJ, Leimbach M, Huber P, Garas S, Sammons BH, McCall SA, Petersen RJ, Bailey DE, Chu H, Mahoney EM, Weintraub WS, Guyton RA. Off-pump coronary artery bypass grafting provides complete revascularization with reduced myocardial injury, transfusion requirements, and length of stay: a prospective randomized comparison of two hundred unselected patients undergoing off-pump versus conventional coronary artery bypass grafting. J Thorac Cardiovasc Surg 2003;125:797-808.

9. Parolari A, Alamanni F, Cannata A, Naliato M, Bonati L, Rubini P, Veglia F, Tremoli E, Biglioli P. Off-pump versus on-pump coronary artery bypass: meta-analysis of currently available randomized trials. Ann Thorac Surg 2003;76:37-40.

10. Subramanian VA, McCabe JC, Geller CM. Minimally invasive direct coronary artery bypass grafting: two-year clinical experience. Ann Thorac Surg 1997;64:1648-1653.

11. Sabik JF, Gillinov AM, Blackstone EH, Vacha C, Houghtaling PL, Navia J, Smedira NG, McCarthy PM, Cosgrove DM, Lytle BW. Does off-pump coronary surgery reduce morbidity and mortality? J Thorac Cardiovasc Surg 2002;124:698-707.
12. Bell MR, Gersh BJ, Schaff HV, Holmes DR Jr, Fisher LD, Alderman EL, Myers WO, Parsons LS, Reeder GS. Effect of completeness of revascularization on long-term outcome of patients with three-vessel disease undergoing coronary artery bypass surgery. A report from the Coronary Artery Surgery Study (CASS) Registry. Circulation 1992;86:446-457.

13. Mack M, Bachand D, Acuff T, Edgerton J, Prince S, Dewey T, Magee M. Improved outcomes in coronary artery bypass grafting with beating-heart techniques. J Thorac Cardiovasc Surg 2002;124:598-607.

14. Bonchek LI. Off-pump coronary bypass: Is it for everyone? J Thorac Cardiovasc Surg 2002;124:431-434.

15. Hernandez F, Cohn WE, Baribeau YR, Tryzelaar JF, Charlesworth DC, Clough RA, Klemperer JD, Morton JR, Westbrook BM, Olmstead EM, O'Connor GT; Northern New England Cardiovascular Disease Study Group. In-hospital outcomes of off-pump versus on-pump coronary artery bypass procedures: a multicenter experience. Ann Thorac Surg 2001;72:1528-1533

16. Sergeant P, Wouters P, Meyns B, Bert C, Van Hemelrijck J, Bogaerts C, Sergeant G, Slabbaert K. OPCAB versus early mortality and morbidity: an issue between clinical relevance and statistical significance. Eur J Cardiothorac Surg 2004;25:779-785.

17. Mack MJ, Pfister A, Bachand D, Emery R, Magee MJ, Connolly M, Subramanian V. Comparison of coronary bypass surgery with and without cardiopulmonary bypass in patients with multivessel disease. J Thorac Cardiovasc Surg 2004; 127:167-173.

18. Sabik JF, Blackstone EH, Lytle BW, Houghtaling PL, Gillinov AM, Cosgrove DM. Equivalent midterm outcomes after off-pump and on-pump coronary surgery. J Thorac Cardiovasc Surg 2004;127:142-148.

19. van der Heijden GJ, Nathoe HM, Jansen EW, Grobbee DE. Meta-analysis on the effect of off-pump coronary bypass surgery. Eur J Cardiothorac Surg 2004;26:81-84.

20. Gundry SR, Romano MA, Shattuck OH, Razzouk AJ, Bailey LL. Seven-year follow-up of coronary artery bypasses performed with and without cardiopulmonary bypass. J Thorac Cardiovasc Surg 1998;115:1273-1277.

21. Cleveland JC Jr, Shroyer AL, Chen AY, Peterson E, Grover FL. Off-pump coronary artery bypass grafting decreases risk-adjusted mortality and morbidity. Ann Thorac Surg 2001;72:1282-1288

22. Czerny M, Baumer H, Kilo J, Zuckermann A, Grubhofer G, Chevtchik O, Wolner E, Grimm M. Complete revascularization in coronary artery bypass grafting with and without cardiopulmonary bypass. Ann Thorac Surg 2001;71:165-169.

23. Khan NE, De Souza A, Mister R, Flather M, Clague J, Davies S, Collins P, Wang D, Sigwart U, Pepper J. A randomized comparison of off-pump and on-pump multivessel coronary-artery bypass surgery. N Engl J Med 2004;350:21-28.

24. Puskas JD, Williams WH, Mahoney EM, Huber PR, Block PC, Duke PG, Staples JR, Glas KE, Marshall JJ, Leimbach ME, McCall SA, Petersen RJ, Bailey DE, Weintraub WS, Guyton RA. Off-pump vs conventional coronary artery bypass grafting: early and 1-year graft patency, cost, and quality-of-life outcomes: a randomized trial. JAMA 2004;291:1841-1849.

25. Van Dijk D, Jansen EW, Hijman R, Nierich AP, Diephuis JC, Moons KG, Lahpor JR, Borst C, Keizer AM, Nathoe HM, Grobbee DE, De Jaegere PP, Kalkman CJ; Octopus Study Group. Cognitive outcome after off-pump and on-pump coronary artery bypass graft surgery: a randomized trial. JAMA 2002;287:1405-1412. 
26. Nathoe HM, van Dijk D, Jansen EW, Suyker WJ, Diephuis JC, van Boven WJ, de la Riviere AB, Borst C, Kalkman CJ, Grobbee DE, Buskens E, de Jaegere PP; Octopus Study Group. A comparison of on-pump and off-pump coronary bypass surgery in low-risk patients. N Engl J Med 2003;348:394-402.

27. Mariani MA, Gu YJ, Boonstra PW, Grandjean JG, van Oeveren W, Ebels T. Procoagulant activity after off-pump coronary operation: is the current anticoagulation adequate? Ann Thorac Surg 1999;67:1370-1375.

28. Quigley RL, Fried DW, Pym J, Highbloom RY. Off-pump coronary artery bypass surgery may produce a hypercoagulable patient. Heart Surg Forum 2003;6:94-98.

29. Kim KB, Lim C, Lee C, Chae IH, Oh BH, Lee MM, Park YB. Off-pump coronary artery bypass may decrease the patency of saphenous vein grafts. Ann Thorac Surg 2001;72:S1033S1037.

30. Omeroglu SN, Kirali K, Guler M, Toker ME, Ipek G, Isik O, Yakut C. Midterm angiographic assessment of coronary artery bypass grafting without cardiopulmonary bypass. Ann Thorac Surg 2000;70:844-849.

31. Kurlansky PA. Is there a hypercoagulable state after off-pump coronary artery bypass surgery? What do we know and what can we do? J Thorac Cardiovasc Surg 2003;126:7-10.

32. Arom KV, Flavin TF, Emery RW, Kshettry VR, Janey PA, Petersen RJ. Safety and efficacy of off-pump coronary artery bypass grafting. Ann Thorac Surg 2000;69:704-710.

33. Stamou SC, Jablonski KA, Pfister AJ, Hill PC, Dullum MK, Bafi AS, Boyce SW, Petro KR, Corso PJ. Stroke after conventional versus minimally invasive coronary artery bypass. Ann Thorac Surg 2002;74:394-399.

34. Patel NC, Deodhar AP, Grayson AD, Pullan DM, Keenan DJ, Hasan R, Fabri BM. Neurological outcomes in coronary surgery: independent effect of avoiding cardiopulmonary bypass. Ann Thorac Surg 2002;74:400-405.

35. Diegeler A, Hirsch R, Schneider F, Schilling LO, Falk V, Rauch T, Mohr FW. Neuromonitoring and neurocognitive outcome in off-pump versus conventional coronary bypass operation. Ann Thorac Surg 2000;69:1162-1166.

36. Lloyd CT, Ascione R, Underwood MJ, Gardner F, Black A, Angelini GD. Serum S-100 protein release and neuropsychologic outcome during coronary revascularization on the beating heart: a prospective randomized study. J Thorac Cardiovasc Surg 2000;119:148-154.

37. Athanasiou T, Al-Ruzzeh S, Kumar P, Crossman MC, Amrani M, Pepper JR, Del Stanbridge R, Casula R, Glenville B. Off-pump myocardial revascularization is associated with less incidence of stroke in elderly patients. Ann Thorac Surg 2004; 77:745-753.

38. Athanasiou T, Aziz O, Mangoush O, Weerasinghe A, Al-Ruzzeh S, Purkayastha S, Pepper J, Amrani M, Glenville B, Casula R. Do off-pump techniques reduce the incidence of postoperative atrial fibrillation in elderly patients undergoing coronary artery bypass grafting? Ann Thorac Surg 2004;77:1567-1574.

39. Akins CW, Boucher CA, Pohost GM. Preservation of interventricular septal function in patients having coronary artery bypass grafts without cardiopulmonary bypass. Am Heart J 1984;107:304-309.

40. Taggart D. Off-pump surgery and cerebral injury. J Thorac Cardiovasc Surg 2004;127:7-9.

41. Roach GW, Kanchuger M, Mangano CM, Newman M, Nussmeier N, Wolman R, Aggarwal A, Marschall K, Graham SH, Ley C. Adverse cerebral outcomes after coronary bypass surgery. Multicenter Study of Perioperative Ischemia Research Group and the Ischemia Research and Education Foundation Investigators. N Engl J Med 1996;335:1857-1863.
42. McKhann GM, Grega MA, Borowicz LM Jr, Bechamps M, Selnes OA, Baumgartner WA, Royall RM. Encephalopathy and stroke after coronary artery bypass grafting: incidence, consequences, and prediction. Arch Neurol 2002;59:1422-1428.

43. Bucerius J, Gummert JF, Borger MA, Walther T, Doll N, Falk V, Schmitt DV, Mohr FW. Predictors of delirium after cardiac surgery delirium: effect of beating-heart (off-pump) surgery. J Thorac Cardiovasc Surg 2004;127:57-64.

44. Boening A, Friedrich C, Hedderich J, Schoettler J, Fraund S, Cremer JT. Early and medium-term results after on-pump and off-pump coronary artery surgery: a propensity score analysis. Ann Thorac Surg 2003;76:2000-2006.

45. Deuse T, Detter C, Samuel V, Boehm DH, Reichenspurner H, Reichart B. Early and midterm results after coronary artery bypass grafting with and without cardiopulmonary bypass: which patient population benefits the most? Heart Surg Forum 2003;6:77-83.

46. Immer FF, Berdat PA, Immer-Bansi AS, Eckstein FS, Muller S, Saner H, Carrel TP. Benefit to quality of life after off-pump versus on-pump coronary bypass surgery. Ann Thorac Surg 2003;76:27-31.

47. Ascione R, Reeves BC, Taylor FC, Seehra HK, Angelini GD. Beating heart against cardioplegic arrest studies (BHACAS 1 and 2): quality of life at mid-term follow-up in two randomised controlled trials. Eur Heart J 2004;25:765-770.

48. Eagle KA, Guyton RA, Davidoff R, Edwards FH, Ewy GA, Gardner TJ, Hart JC, Herrmann HC, Hillis LD, Hutter Jr AM, Lytle BW, Marlow RA, Nugent WC, Orszulak TA, Antman EM, Smith Jr SC, Alpert JS, Anderson JL, Faxon DP, Fuster V, Gibbons RJ, Gregoratos G, Halperin JL, Hiratzka LF, Hunt SA, Jacobs AK, Ornato JP. ACC/AHA 2004 Guideline Update for Coronary Artery Bypass Graft Surgery: Summary Article: A Report of the American College of Cardiology/American Heart Association Task Force on Practice Guidelines (Committee to Update the 1999 Guidelines for Coronary Artery Bypass Graft Surgery). Circulation 2004;110:1168-1176.

\section{Author Affiliation}

John Pepper, M.Chir, FRCS, Department of Surgery, Royal Brompton Hospital, Sydney Street, London SW3 6NP, United Kingdom 